\title{
Cascade radical reaction of substrates with a carbon-carbon triple bond as a radical acceptor
}

\author{
Hideto Miyabe ${ }^{* 1,2}$, Ryuta Asada ${ }^{2}$ and Yoshiji Takemoto ${ }^{*}$
}

\section{Full Research Paper}

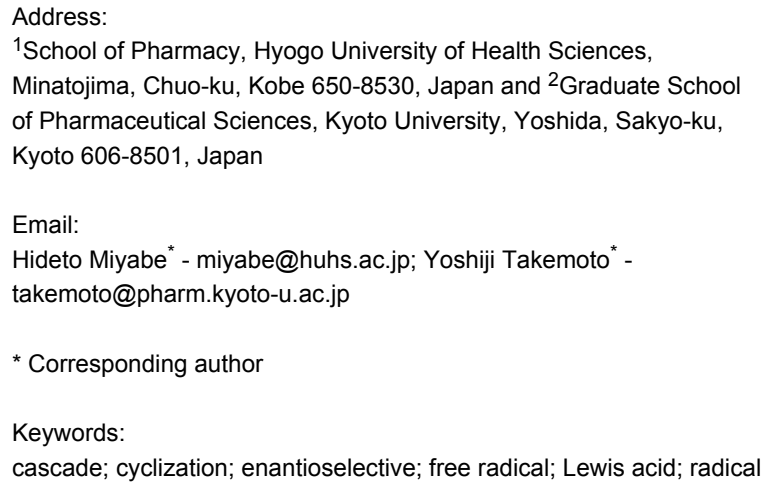

Beilstein J. Org. Chem. 2013, 9, 1148-1155. doi:10.3762/bjoc. 9.128

Received: 08 April 2013

Accepted: 22 May 2013

Published: 13 June 2013

This article is part of the Thematic Series "Organic free radical chemistry".

Guest Editor: C. Stephenson

(C) 2013 Miyabe et al; licensee Beilstein-Institut License and terms: see end of document.

\begin{abstract}
The limitation of hydroxamate ester as a chiral Lewis acid coordination moiety was first shown in an intermolecular reaction involving a radical addition and sequential allylation processes. Next, the effect of hydroxamate ester was studied in the cascade addition-cyclization-trapping reaction of substrates with a carbon-carbon triple bond as a radical acceptor. When substrates with a methacryloyl moiety and a carbon-carbon triple bond as two polarity-different radical acceptors were employed, the cascade reaction proceeded effectively. A high level of enantioselectivity was also obtained by a proper combination of chiral Lewis acid and these substrates.
\end{abstract}

\section{Introduction}

Strategies involving a cascade process offer the advantage of multiple carbon-carbon and/or carbon-heteroatom bond formations in a single operation. Radical chemistry has been developed as one of the most powerful tools for carbon-carbon bond formation in organic synthesis [1-20]. Particularly, the advantages for utilizing the radical methodologies are the high functional group tolerance and the mild reaction conditions, because radical intermediates are not charged species. Therefore, a number of extensive investigations into sequential radical reactions have been reported over the past fifteen years and significant progress has been made in recent years [21-36]. We have

also directed our efforts toward the development of new and efficient cascade approaches for the construction of carbon-carbon/heteroatom bonds based on radical chemistry. These approaches can be classified into two categories according to their reaction mechanism (Figure 1) [37-43].

Enantioselective radical reactions have been intensively studied over the past fifteen years. Compared with stereocontrol studies on intermolecular radical reactions, the enantioselective stereocontrol in radical cyclizations still remains a major challenge [44-68]. We have also investigated a new type of chiral Lewis 


\section{1) Reaction via radical-ionic process}

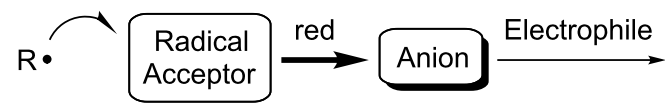

\section{2) Reaction via radical-radical process}

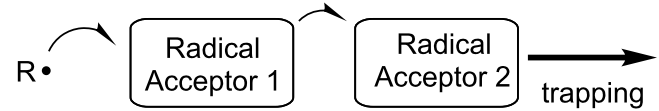

Figure 1: Cascade bond formation based on radical reactions

acid mediated cyclization approach for cascade bond-forming reactions via sequential radical-radical processes (Figure 2) [39-43]. In these studies, the control of the enantioselectivities was achieved by the introduction of a hydroxamate ester as a two-point-binding coordination tether into the middle of substrates A, together with the control of the rotamer population of substrates $[39,42]$. In this paper, we describe in detail the cascade addition-cyclization-trapping reaction of substrates with a carbon-carbon triple bond as a radical acceptor as well as the effect of hydroxamate ester as a Lewis acid coordination moiety. Some results have been reported in our preliminary communication [39].
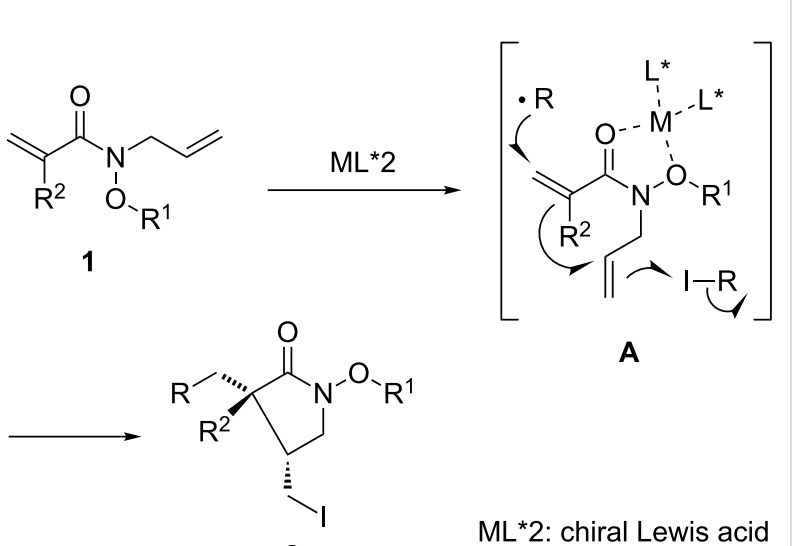

A

$M L * 2$ : chiral Lewis acid

Figure 2: Our method for controlling the geometry of substrates and the stereochemistry of cyclization.

\section{Results and Discussion}

Renaud's group showed in 2002 that hydroxamic acid derivatives are useful achiral templates in enantioselective Diels-Alder reactions $[69,70]$. To study the effect of hydroxamate ester as an achiral template in the intermolecular radical reaction, our experiments began with the investigation of cascade radical addition-allylation of hydroxamate esters $\mathbf{3 A}-\mathbf{C}$ having an acryloyl moiety (Scheme 1). The reactions were eval- uated in $\mathrm{CH}_{2} \mathrm{Cl}_{2}$ at $-78{ }^{\circ} \mathrm{C}$ by employing isopropyl iodide, allyltin reagent, and $\mathrm{Et}_{3} \mathrm{~B}$ as a radical initiator. The enantiomeric purities of products were checked by chiral HPLC analysis. The effect of the substituents $\mathrm{R}^{1}$ and $\mathrm{R}^{2}$ of hydroxamate esters $\mathbf{3 A}-\mathbf{C}$ on yield and selectivity was evaluated in the presence of a chiral Lewis acid prepared from box ligand L1 and $\mathrm{Zn}(\mathrm{OTf})_{2}$. The results are shown in Scheme 1. Although good enantioselectivities were not observed, the size of the substituents had an impact on enantioselectivity with the larger group leading to lower ee. These observations indicate that the formation of the rigid ternary complex of hydroxamate ester, $\mathrm{Zn}(\mathrm{OTf})_{2}$ and the ligand $\mathbf{L} \mathbf{1}$ is required for enantioselective transformation. A similar trend was observed in our studies on the addition-cyclization-trapping reaction of hydroxamate esters $[39,42]$. The chiral Lewis acid promoted the reaction of substrate 3A having a bulky 2-naphthylmethyl group as substituent $\mathrm{R}^{2}$ to form the product $\mathbf{4 A}$ in $40 \%$ yield with $7 \%$ ee. Moderate enantioselectivity was observed by employing the substrate 3B having a benzyl group as $\mathrm{R}^{1}$ and a methyl group as $\mathrm{R}^{2}$. Particularly, the steric factor of the fluxional substituent $\mathrm{R}^{1}$ affected not only enantioselectivity but also the chemical efficiency. The use of $\mathbf{3 C}$ having a 2-naphthylmethyl group as $\mathrm{R}^{1}$ led to a decrease in the chemical yield, probably because of the steric repulsion by a bulky substituent $\mathrm{R}^{1}$ leading to the dissociation of the chiral Lewis acid. In these studies, the absolute configuration at newly generated stereocenters has been not determined.

We recently reported in detail the cascade addition-cyclization-trapping reaction of substrates with

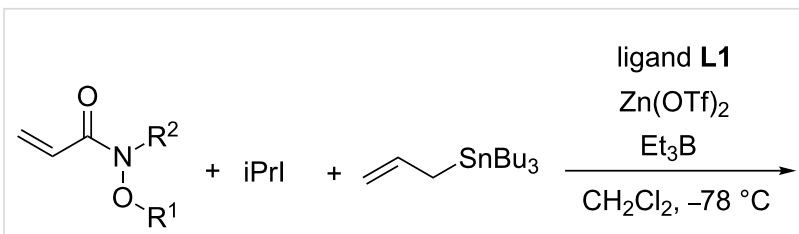

3A: $R^{1}=M e, R^{2}=2$-naphthylmethyl

3B: $R^{1}=B n, R^{2}=M e$

3C: $R^{1}=2$-naphthylmethyl, $R^{2}=M e$<smiles>[R]ON([R])C(=O)C(C[In])CC=C</smiles>

4A $(40 \%, 7 \%$ ee $)$

4B $(57 \%, 30 \%$ ee $)$

4C (5\%, racemic)

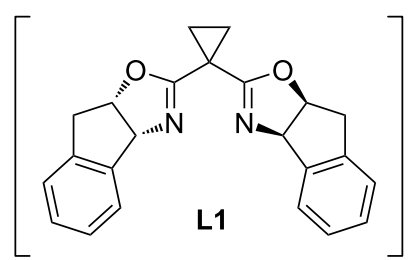

Scheme 1: Effect of hydroxamate ester on intermolecular $\mathrm{C}-\mathrm{C}$ bondforming reactions. 
carbon-carbon double bonds as two kinds of polarity-different radical acceptors [42]. On the basis of these results, the possibility of the carbon-carbon triple bond as a radical acceptor and the hydroxamate ester functionality as a two-point-binding coordination tether was next studied in detail. To understand the scope and limitation of the cascade transformation of hydroxamate esters with carbon-carbon triple bonds, the substrates of choice were 5, 6A-C, 7 and 8 having hydroxamate ester functionality (Figure 3).<smiles>C#CCN(Cc1ccccc1)C(=O)C=C</smiles>

5<smiles>C#CCN(OCc1ccccc1)C(=O)C#C</smiles>

7<smiles>[R]ON(CC#C)C(=O)C(=C)C</smiles>

6A: $R^{1}=M e$

6B: $\mathrm{R}^{1}=\mathrm{Bn}$

6C: $R^{1}=2$-naphthylmethyl<smiles>C#CC(=O)N(CC1OCCO1)OCc1ccccc1</smiles>

8
Figure 3: Substrates for testing the cascade transformation.

At first, we studied the cascade reaction of $\mathbf{5}$ with an acryloyl moiety and $6 \mathrm{~A}-\mathrm{C}$ with a methacryloyl moiety as an electrondeficient acceptor in the absence of a chiral ligand (Scheme 2). To control the rotamer population of substrates, $\mathrm{Zn}(\mathrm{OTf})_{2}$ was used as a Lewis acid to coordinate the hydroxamate ester functionality. The reactions were evaluated in $\mathrm{CH}_{2} \mathrm{Cl}_{2}$ at $20{ }^{\circ} \mathrm{C}$ under the tin-free iodine atom transfer conditions by using isopropyl iodide and $\mathrm{Et}_{3} \mathrm{~B}$. The reaction of hydroxamate ester $\mathbf{5}$ did not give the desired product probably due to polymerization of 5 through the labile acrylamide moiety. In contrast, the reaction of $6 \mathbf{A}-\mathbf{C}$ proceeded effectively to give the cyclic products 9Aa-9Ca in good yields. Among them, hydroxamate esters 6A and $6 \mathrm{~B}$, which have a small methyl or benzyl group as $\mathrm{R}^{1}$, have shown a high reactivity, although a $76 \%$ yield of product $9 \mathrm{Ca}$ was obtained even when hydroxamate ester $\mathbf{6 C}$ having a 2-naphthylmethyl group was used. Furthermore, the regiochemical course of the initial radical addition to $6 \mathbf{A}-\mathbf{C}$ was well controlled. The nucleophilic isopropyl radical reacted selectively with the electron-deficient methacryloyl moiety to give the single isomers $9 \mathbf{A a}-\mathbf{9 C a}$.

It is also important to note that Z-isomers 9Aa-9Ca were selectively obtained without the formation of corresponding $E$-isomers. The $E, Z$-selectivities are determined by capturing the intermediate vinyl radicals with an atom-transfer reagent

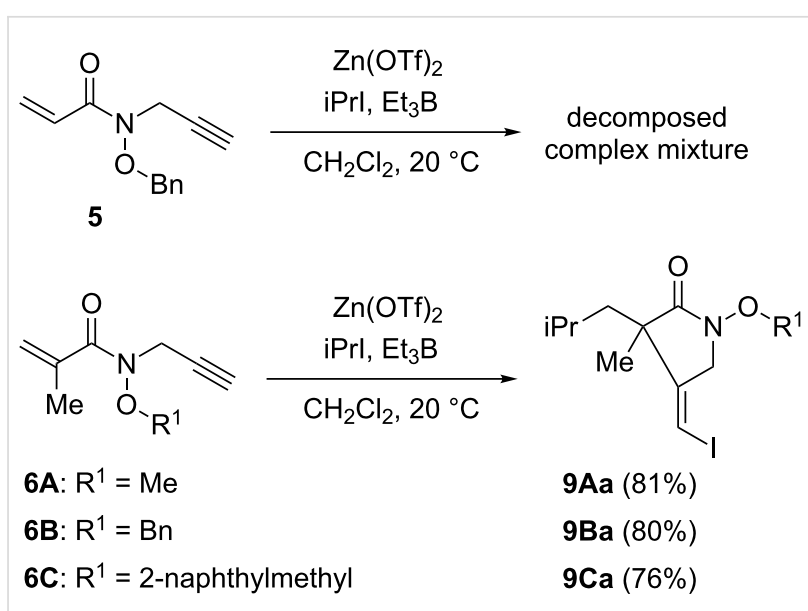

Scheme 2: Cascade radical addition-cyclization-trapping reaction of 5 and $6 \mathrm{~A}-\mathrm{C}$.

such as isopropyl iodide (Figure 4). These selectivities are controlled by the steric factor around vinyl radicals. The vinyl radicals are $\sigma$-radicals in a very fast equilibrium between $E$-isomer $\mathbf{B}$ and $Z$-isomer $\mathbf{C}$. The steric hindrance between the substituents on the $\alpha$-carbon atom of radical $\mathbf{C}$ and isopropyl iodide is assumed to lead to selective iodine atom-transfer in radical $\mathbf{B}$ giving $\mathbf{9 A a}-\mathbf{9 C a}$ as single $Z$-isomers.

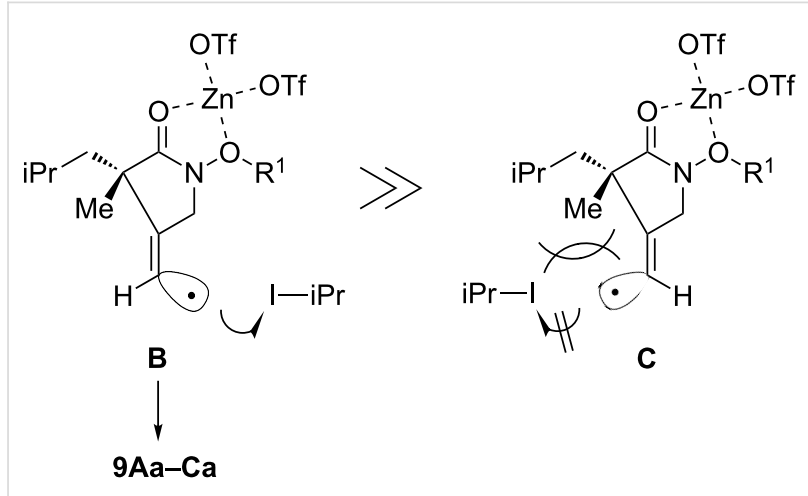

Figure 4: E/Z-selectivity of $9 \mathrm{Aa}-\mathrm{Ca}$.

On the basis of the above results, we next studied the reaction of $6 \mathrm{~A}-\mathrm{C}$ at $-78^{\circ} \mathrm{C}$ in the presence of $\mathrm{Zn}(\mathrm{OTf})_{2}$ and chiral box ligands L1-L3 (Scheme 3 and Table 1). A stoichiometric amount of chiral Lewis acid prepared from $\mathrm{Zn}(\mathrm{OTf})_{2}$ and ligand $\mathbf{L 1}$ accelerated the reaction of hydroxamate ester $6 \mathbf{A}$ having a methyl group as substituent $\mathrm{R}^{1}$ (Table 1 , entry 1 ), although the reaction of $6 \mathrm{~A}$ did not proceed effectively at $-78{ }^{\circ} \mathrm{C}$ in the absence of box ligand L1. The desired product 9Aa was isolated as a single isomer in $51 \%$ yield with $60 \%$ ee after being stirred for $10 \mathrm{~h}$. The use of hydroxamate ester 6B having a benzyl group led to not only an enhancement in chemical yield but also to an improvement in enantioselectivity to give the pro- 


$$
\text { 6A-C } \begin{array}{ll}
\begin{array}{l}
\text { ligand L1-L3 } \\
\mathrm{Zn}(\mathrm{OTf})_{2}
\end{array} \\
\begin{array}{l}
\mathrm{R}^{2}, \mathrm{Et}_{3} \mathrm{~B} \\
\mathrm{CH}_{2} \mathrm{Cl}_{2}
\end{array} \\
-78^{\circ} \mathrm{C}
\end{array}
$$<smiles>c1ccc2c(c1)CC1OC(CC3=N[C@@H]4c5ccccc5C[C@H]4N3)=N[C@H]21</smiles>
L2<smiles>c1ccc(C2OC(CC3=NC(c4ccccc4)[C@@H](c4ccccc4)O3)=N[C@@H]2c2ccccc2)cc1</smiles>

L3
Scheme 3: Enantioselective cascade reaction of 6A-C

duct 9Ba in $87 \%$ yield with $80 \%$ ee (Table 1 , entry 2 ). Next, the catalytic nature of the reactions was examined (Table 1, entries $3-5)$. The reactions proceeded equally well with 50 and $30 \mathrm{~mol}$ $\%$ of chiral Lewis acid as with a stoichiometric amount (Table 1, entry 3 and 4). Further reduction of the chiral Lewis acid load to $10 \mathrm{~mol} \%$ resulted in a decrease of both the chemical yield and enantioselectivity (Table 1 , entry 5 ). In the case of $10 \mathrm{~mol} \%$ of the chiral Lewis acid, the ternary complex of the ligand, the Lewis acid and the substrate were not effectively formed, and the background reaction giving the racemic product proceeded. Additionally, the high $Z$-selectivity of product 9Ba indicates that the stereoselective iodine-atom transfer from isopropyl iodide to an intermediate radical proceeded effectively under these catalytic reaction conditions. The reaction using box ligand $\mathbf{L} 2$ instead of $\mathbf{L} \mathbf{1}$ attenuated the enantioselectivity (Table 1, entry 6). A somewhat lower enantio- selectivity was obtained by using ligand L3, surprisingly resulting in antipode product $\mathbf{9 B a}$ (Table 1, entry 7). The representative effect of the solvent is shown in Table 1, entries $8-10$. No reaction occurred in toluene, owing to the low solubility of the chiral Lewis acid in toluene (Table 1, entry 8). When the reaction was carried out in toluene $/ \mathrm{CH}_{2} \mathrm{Cl}_{2}(4: 1, \mathrm{v} / \mathrm{v})$, the cyclic product 9Ba was obtained in $67 \%$ yield with $77 \%$ ee (Table 1, entry 9). The reaction in the protic solvent $\mathrm{MeOH}$ gave the nearly racemic product, although the high $Z$-selectivity was maintained (Table 1, entry 10). These results suggest that the rigid chelation of the chiral Lewis acid to the hydroxamate ester functionality occured in $\mathrm{CH}_{2} \mathrm{Cl}_{2}$. In the presence of chiral Lewis acid, hydroxamate ester $\mathbf{6 C}$ had also shown good reactivity, although the enantioselectivity diminished to $75 \%$ ee (Table 1, entry 11). We next studied the reaction of substrate $6 \mathbf{B}$ with other radical precursors (Table 1, entries 12-14). Reactions with cyclohexyl and cyclopentyl radicals were also facile. Under analogous reaction conditions, an outstanding level of enantioselectivity was observed on employing the bulky tertbutyl iodide as a radical precursor (Table 1, entry 14). A good yield of the product 9 Bd was obtained with $92 \%$ ee and high

\begin{tabular}{|c|c|c|c|c|c|c|c|}
\hline entry & substrate & $\mathrm{R}^{2}$ & ligand & $\begin{array}{l}\text { Lewis acid } \\
\text { (equiv) }\end{array}$ & $\begin{array}{l}\text { product } \\
\text { (\% yield) }\end{array}$ & ZIE & ee $(\%)$ \\
\hline 1 & $6 A$ & $\mathrm{iPr}$ & L1 & 1.0 & 9Aa (51) & $>98: 2$ & 60 \\
\hline 2 [39] & $6 B$ & $\mathrm{iPr}$ & L1 & 1.0 & 9Ba (87) & $>98: 2$ & 80 \\
\hline 3 [39] & $6 B$ & $\mathrm{iPr}$ & L1 & 0.5 & 9Ba (85) & $>98: 2$ & 81 \\
\hline 4 [39] & $6 B$ & $\mathrm{iPr}$ & L1 & 0.3 & 9Ba (82) & $>98: 2$ & 81 \\
\hline 5 [39] & $6 B$ & $\mathrm{iPr}$ & L1 & 0.1 & $9 \mathrm{Ba}(49)^{\mathrm{a}}$ & $>98: 2$ & 47 \\
\hline 6 & $6 B$ & $\mathrm{iPr}$ & L2 & 1.0 & 9Ba (76) & $>98: 2$ & 71 \\
\hline 7 & $6 B$ & $\mathrm{iPr}$ & L3 & 1.0 & 9Ba (81) & $>98: 2$ & -69 \\
\hline $8^{b}$ & $6 B$ & iPr & L1 & 1.0 & no reaction & & \\
\hline $9^{c}$ & $6 B$ & $\mathrm{iPr}$ & L1 & 1.0 & $9 \mathrm{Ba}(67)$ & $>98: 2$ & 77 \\
\hline $10^{d}$ & $6 B$ & $\mathrm{iPr}$ & L1 & 1.0 & 9Ba (63) & $>98: 2$ & rac \\
\hline 11 & $6 C$ & $\mathrm{iPr}$ & L1 & 1.0 & 9Ca (83) & $>98: 2$ & 75 \\
\hline 12 [39] & $6 B$ & $c$-Hex & L1 & 1.0 & 9Bb (82) & $>98: 2$ & 81 \\
\hline 13 & $6 B$ & $c$-Pent & L1 & 1.0 & 9Bc (83) & $>98: 2$ & 79 \\
\hline 14 [39] & $6 B$ & $t-\mathrm{Bu}$ & L1 & 1.0 & 9Bd (85) & $>98: 2$ & 92 \\
\hline
\end{tabular}
Z-selectivity.

The absolute configuration at the newly generated stereocenters of 9Aa-Bd was assumed by similarity between the present reaction and the previously reported reaction of substrates having the carbon-carbon double bond $[39,42]$. In these reactions, a ternary complex of ligand, Lewis acid and substrate would control the three-dimensional arrangement of two radical acceptors. A tetrahedral or cis-octahedral geometry around the zinc center was proposed [71,72]. In Figure 5, a tentative model

${ }^{a}$ starting substrate $6 \mathrm{~B}$ was recovered in $29 \%$ yield; ${ }^{\mathrm{b}}$ in toluene; ${ }^{\mathrm{c}}$ in toluene/ $\mathrm{CH}_{2} \mathrm{Cl}_{2}(4: 1, \mathrm{v} / \mathrm{v})$; ${ }_{\text {in }} \mathrm{MeOH}$. 


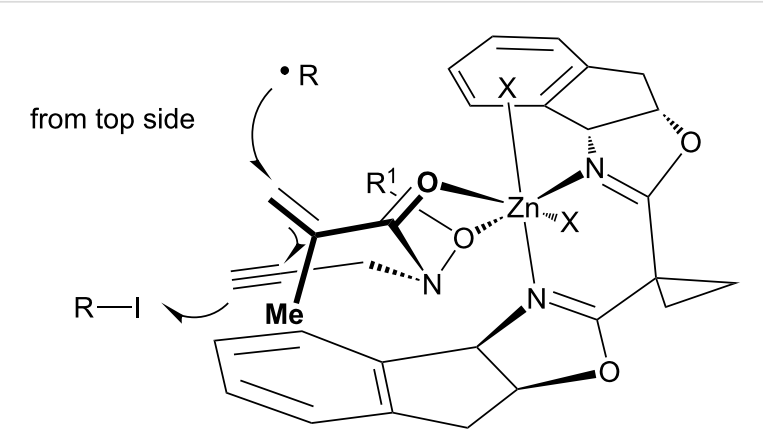

Figure 5: Model for the enantioselective reaction.

of an octahedral complex is shown, in which two oxygen atoms of the hydroxamate ester functionality occupy two equatorial positions.

To study the effect of an electron-deficient acceptor on the cascade process, the reactions of propiolic acid derivatives 7 and $\mathbf{8}$ were tested (Scheme 4). At first, the reaction of 7 was evaluated under asymmetric reaction conditions. However, the cascade addition-cyclization-trapping reaction did not proceed, and the simple adduct $\mathbf{1 0}$ was formed in $57 \%$ yield by the addition-trapping process. Next, the reaction of propiolic acid derivative 8 was tested, because we expected the [1,5]-hydrogen shift from 1,3-dioxolane ring into the reactive vinyl radical as shown as D. However, the simple adduct $\mathbf{1 1}$ was only obtained<smiles>C#CCN(OCc1ccccc1)C(=O)C(I)=CC(C)C</smiles><smiles>C#CC(=O)N(CC1OCCO1)OCC(C)C</smiles>

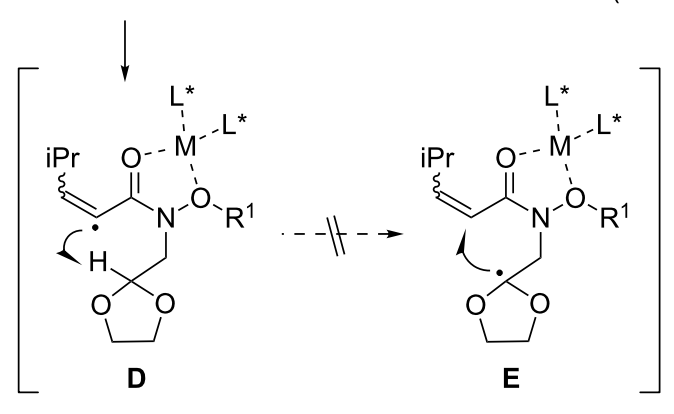

Scheme 4: Reaction of propiolic acid derivatives 7 and 8. in $78 \%$ yield. The results from these studies show that a carbon-carbon double bond, e.g., a methacryloyl group, of the electron-deficient acceptor is essential for the successful cascade transformation.

To gain further insight into the stereocontrol in the cyclization step, we next studied the opposite regiochemical cyclization by using the substrate $\mathbf{1 2}$ via the intermediate radical $\mathbf{F}$ (Scheme 5). The reaction was carried out in the presence of $\mathrm{Bu}_{3} \mathrm{SnH}$ under asymmetric reaction conditions. Although the reaction proceeded even at $-78{ }^{\circ} \mathrm{C}$, the nearly racemic product 13 was isolated in $60 \%$ yield. This observation indicates that the regiochemical course of the cyclization step is an important factor to achieve the highly asymmetric induction.

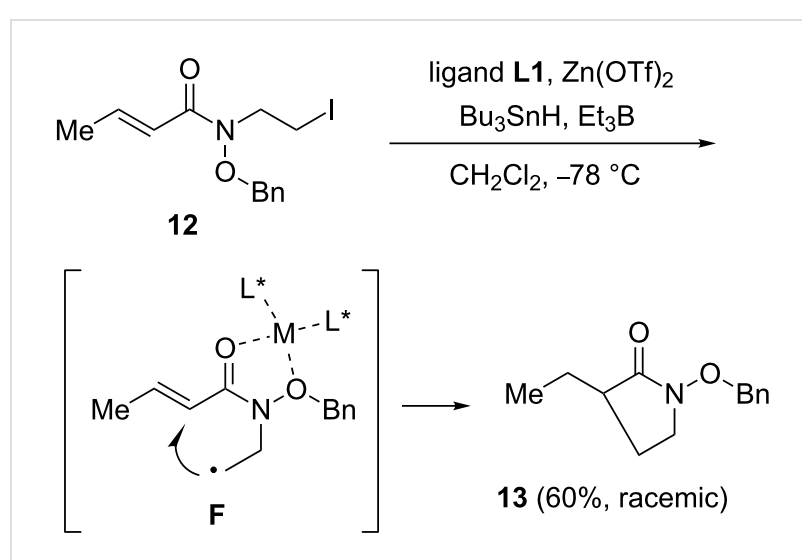

Scheme 5: Opposite regiochemical cyclization using substrate 12.

We next investigated the reactivity of internal alkynes as electron-rich acceptors (Scheme 6). The internal alkyne $\mathbf{1 4}$ has shown a good reactivity comparable to that of the terminal alkynes 6A-C. In the absence of a chiral ligand, the zinc Lewis acid accelerated the reaction of alkyne $\mathbf{1 4}$ with an isopropyl radical at $20{ }^{\circ} \mathrm{C}$ to give the desired cyclic product $15 \mathbf{a}$ in $73 \%$ yield. Under analogous reaction conditions, both cyclohexyl iodide and cyclopentyl iodide worked well to give $\mathbf{1 5 b}$ and $\mathbf{1 5 c}$

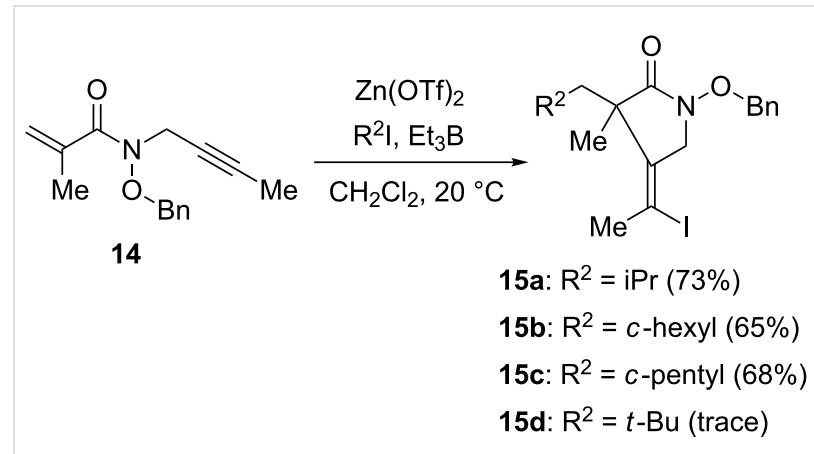

Scheme 6: Cascade reaction of 14 
in $65 \%$ and $68 \%$ yields, respectively. However, the reaction with a bulky tert-butyl radical did not proceed effectively, probably due to side reactions such as polymerization.

We finally investigated the enantioselective reaction of internal alkynes 14 and 16 (Scheme 7). The reaction of 14 proceeded with good enantioselectivities (Table 2). When a stoichiometric amount of chiral Lewis acid was employed, the reaction with an isopropyl radical gave the desired product $15 \mathbf{a}$ in $86 \%$ yield with $83 \%$ ee (Table 2 , entry 1 ). The reaction proceeded equally well with $30 \mathrm{~mol} \%$ of chiral Lewis acid as with a stoichiometric amount (Table 2, entry 2). The secondary radicals, generated from cyclohexyl iodide or cyclopentyl iodide, reacted well to afford $\mathbf{1 5 b}$ and $\mathbf{1 5 c}$ with $85 \%$ ee and $83 \%$ ee, respectively (Table 2, entry 3 and 4). In marked contrast to the reaction in the absence of a chiral ligand (Scheme 6), the use of bulky tertbutyl iodide led to not only an enhancement in chemical yield but also to an improvement in enantioselectivity (Table 2, entry 5). These observations indicate that the combination of chiral Lewis acid and hydroxamate ester functionality led the rigid complex promoting the cyclization step and suppressing the background reaction or the undesired side reactions. High chemical yield and enantioselectivity were observed with $50 \mathrm{~mol} \%$ of chiral Lewis acid (Table 2, entry 6), although further reduction of the catalyst load to $30 \mathrm{~mol} \%$ resulted in a decrease of yield and enantioselectivity (Table 2, entry 7). Both chemical yield and enantioselectivity decreased by changing Lewis acid from $\mathrm{Zn}(\mathrm{OTf})_{2}$ to $\mathrm{MgI}_{2}$ (Table 2, entry 8). When the more nucleophilic and stable tert-butyl radical was employed, the reaction of substrate $\mathbf{1 6}$ having a phenyl group at the terminal position proceeded smoothly to give the desired product $\mathbf{1 7}$ in $89 \%$ yield with $67 \%$ ee (Table 2 , entry 9 ). It is also important to note that the high $Z / E$-selectivity of products was observed even when internal alkynes 14 and 16 were employed. These results indicate that the iodine atom-transfer from $R^{2} I$ to the substituted vinyl radicals proceeded stereoselectively.

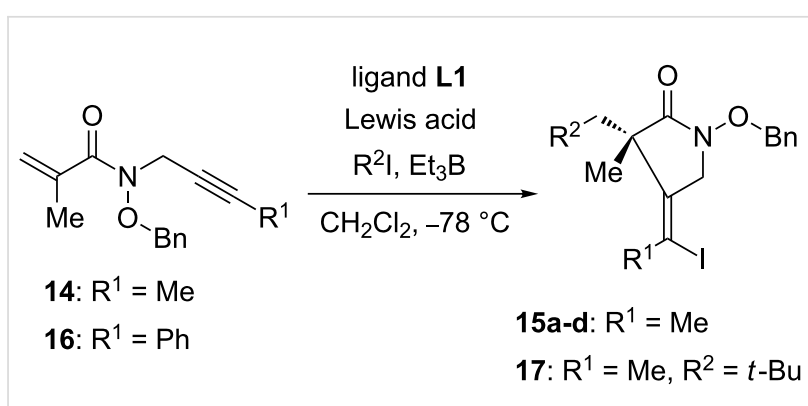

Scheme 7: Enantioselective cascade reaction of 14 and 16.

Particularly, the substrate $\mathbf{1 6}$ having a phenyl group gave the intermediate linear $\pi$-radical. Thus, the capture of linear vinyl radical with atom-transfer reagent would be influenced by the steric hindrance around the quaternary carbon atom [43].

\section{Conclusion}

We have shown the cascade radical addition-cyclization-trapping reaction of substrates with a carbon-carbon triple bond as a radical acceptor as well as the scope and limitation of hydroxamate ester as a coordination site with a chiral Lewis acid. Synthetic strategies involving enantioselective radical cyclizations would be desirable tools for preparing functionalized cyclic compounds with multiple stereocenters. These studies offer opportunities for further exploration of fascinating possibilities in the realm of cascade radical reactions.

\section{Supporting Information}

\section{Supporting Information File 1}

General experimental procedures, characterization data of obtained compounds, and preparation of substrates. [http://www.beilstein-journals.org/bjoc/content/ supplementary/1860-5397-9-128-S1.pdf]

\begin{tabular}{|c|c|c|c|c|c|c|}
\hline entry & substrate & $\mathrm{R}^{2}$ & $\begin{array}{l}\text { Lewis acid } \\
\text { (equiv) }\end{array}$ & yield $(\%)$ & ratio & ee $(\%)$ \\
\hline 1 [39] & 14 & $\mathrm{iPr}$ & $\mathrm{Zn}(\mathrm{OTf})_{2}(1.0)$ & 86 & $>98: 2$ & 83 \\
\hline $2[39]$ & 14 & $\mathrm{iPr}$ & $\mathrm{Zn}(\mathrm{OTf})_{2}(0.3)$ & 74 & $>98: 2$ & 81 \\
\hline 3 [39] & 14 & $c$-Hex & $\mathrm{Zn}(\mathrm{OTf})_{2}(1.0)$ & 87 & $>98: 2$ & 85 \\
\hline 4 & 14 & $c$-Pent & $\mathrm{Zn}(\mathrm{OTf})_{2}(1.0)$ & 77 & $>98: 2$ & 83 \\
\hline 5 [39] & 14 & $t-\mathrm{Bu}$ & $\mathrm{Zn}(\mathrm{OTf})_{2}(1.0)$ & 94 & $>98: 2$ & 90 \\
\hline 6 & 14 & $t-\mathrm{Bu}$ & $\mathrm{Zn}(\mathrm{OTf})_{2}(0.5)$ & 94 & $>98: 2$ & 91 \\
\hline 7 & 14 & $t-\mathrm{Bu}$ & $\mathrm{Zn}(\mathrm{OTf})_{2}(0.3)$ & 75 & $>98: 2$ & 61 \\
\hline 8 & 14 & $t$-Bu & $\mathrm{MgI}_{2}(1.0)$ & 20 & $>98: 2$ & 54 \\
\hline 9 & 16 & $t-\mathrm{Bu}$ & $\mathrm{Zn}(\mathrm{OTf})_{2}(1.0)$ & 89 & $>98: 2$ & 67 \\
\hline
\end{tabular}




\section{Acknowledgements}

This work was supported in part by a Grant-in-Aid for Scientific Research (C) (H.M.) from the Ministry of Education, Culture, Sports, Science and Technology of Japan.

\section{References}

1. Smadja, W. Synlett 1994, 1-26. doi:10.1055/s-1994-22728

2. Fallis, A. G.; Brinza, I. M. Tetrahedron 1997, 53, 17543-17594. doi:10.1016/S0040-4020(97)10060-6

3. Renaud, P.; Gerster, M. Angew. Chem., Int. Ed. 1998, 37, 2562-2579. doi:10.1002/(SICI)1521-3773(19981016)37:19<2562::AID-ANIE2562>3 .0.CO;2-D

4. Sibi, M. P.; Porter, N. A. Acc. Chem. Res. 1999, 32, 163-171. doi:10.1021/ar9600547

5. Naito, T. Heterocycles 1999, 50, 505-541. doi:10.3987/REV-98-SR(H)2

6. Renaud, P.; Sibi, M. P., Eds. Radicals in Organic Synthesis; Wiley-VCH: Weinheim, Germany, 2001; Vol. 1 and 2.

7. Bar, G.; Parsons, A. F. Chem. Soc. Rev. 2003, 32, 251-263. doi:10.1039/b111414j

8. Sibi, M. P.; Manyem, S.; Zimmerman, J. Chem. Rev. 2003, 103, 3263-3296. doi:10.1021/cr020044I

9. Srikanth, G. S. C.; Castle, S. L. Tetrahedron 2005, 61, 10377-10441. doi:10.1016/j.tet.2005.07.077

10. Guo, H.-C.; Ma, J.-A. Angew. Chem., Int. Ed. 2006, 45, 354-366. doi:10.1002/anie.200500195

11. Zimmerman, J.; Sibi, M. P. Top. Curr. Chem. 2006, 263, 107-162. doi:10.1007/128_027

12. Godineau, E.; Landais, Y. Chem.-Eur. J. 2009, 15, 3044-3055. doi:10.1002/chem.200802415

13. Rowlands, G. J. Tetrahedron 2009, 65, 8603-8655. doi:10.1016/j.tet.2009.07.001

14. Rowlands, G. J. Tetrahedron 2010, 66, 1593-1636. doi:10.1016/j.tet.2009.12.023

15. Perchyonok, V. T. Radical Reactions in Aqueous Media. In RSC Green Chemistry, No. 6, RSC Publishing: Cambridge, 2010.

16. Narayanam, J. M. R.; Stephenson, C. R. J. Chem. Soc. Rev. 2011, 40, 102-113. doi:10.1039/b913880n

17. Yang, Y.-H.; Sibi, P. Stereoselective Radical Reactions. In Encyclopedia of Radicals in Chemistry, Biology and Materials; Chatgilialoglu, C.; Studer, A., Eds.; Wiley: Weinheim, Germany, 2012; Vol. 2, pp 655-692. doi:10.1002/9781119953678.rad019

18. Ischay, M. A.; Yoon, T. P. Eur. J. Org. Chem. 2012, 3359-3372. doi:10.1002/ejoc.201101071

19. Shi, L.; Xia, W. Chem. Soc. Rev. 2012, 41, 7687-7697. doi:10.1039/c2cs35203f

20. Tucker, J. W.; Stephenson, C. R. J. J. Org. Chem. 2012, 77, 1617-1622. doi:10.1021/jo202538x

21. Nozaki, K.; Oshima, K.; Utimoto, K. Tetrahedron Lett. 1988, 29 , 1041-1044. doi:10.1016/0040-4039(88)85330-9

22. Curran, D. P.; Chen, M. H.; Spletzer, E.; Seong, C. M.; Chang, C. T. J. Am. Chem. Soc. 1989, 111, 8872-8878. doi:10.1021/ja00206a016

23. Giese, B.; Zehnder, M.; Roth, M.; Zeitz, H.-G. J. Am. Chem. Soc. 1990, 112, 6741-6742. doi:10.1021/ja00174a061

24. Porter, N. A.; Rosenstein, I. J.; Breyer, R. A.; Bruhnke, J. D.; Wu, W. X.; McPhail, A. T. J. Am. Chem. Soc. 1992, 114, 7664-7676. doi:10.1021/ja00046a010

25. Marco-Contelles, J. Chem. Commun. 1996, 2629-2630. doi:10.1039/cc9960002629
26. Takai, K.; Matsukawa, N.; Takahashi, A.; Fujii, T. Angew. Chem., Int. Ed. 1998, 37, 152-155. doi:10.1002/(SICI)1521-3773(19980202)37:1/2<152::AID-ANIE152>3.3 .CO;2-\#

27. Miyabe, H.; Fujii, K.; Goto, T.; Naito, T. Org. Lett. 2000, 2, 4071-4074. doi:10.1021/ol006716g

28. Sibi, M. P.; Chen, J. J. Am. Chem. Soc. 2001, 123, 9472-9473. doi:10.1021/ja016633a

29. Dhimane, A.-L.; Aïssa, C.; Malacria, M. Angew. Chem., Int. Ed. 2002, 41, 3284-3287. doi:10.1002/1521-3773(20020902)41:17<3284::AID-ANIE3284>3.0.CO ;2-Z

30. Yamago, S.; Miyoshi, M.; Miyazoe, H.; Yoshida, J. Angew. Chem., Int. Ed. 2002, 41, 1407-1409. doi:10.1002/1521-3773(20020415)41:8<1407::AID-ANIE1407>3.0.CO; $2-Z$

31. Bazin, S.; Feray, L.; Siri, D.; Naubron, J.-V.; Bertrand, M. P. Chem. Commun. 2002, 2506-2507. doi:10.1039/b206695e

32. Tsuchii, K.; Doi, M.; Hirao, T.; Ogawa, A. Angew. Chem., Int. Ed. 2003, 42, 3490-3493. doi:10.1002/anie.200250790

33. Denes, F.; Chemla, F.; Normant, J. F. Angew. Chem., Int. Ed. 2003, 42, 4043-4046. doi:10.1002/anie.200250474

34. Yamamoto, Y.; Nakano, S.; Maekawa, H.; Nishiguchi, I. Org. Lett. 2004, 6, 799-802. doi:10.1021/ol036506e

35. Uenoyama, Y.; Fukuyama, T.; Nobuta, O.; Matsubara, H.; Ryu, I. Angew. Chem., Int. Ed. 2005, 44, 1075-1078. doi:10.1002/anie.200461954

36. Ueda, U.; Miyabe, H.; Sugino, H.; Miyata, O.; Naito, T. Angew. Chem., Int. Ed. 2005, 44, 6190-6193. doi:10.1002/anie.200502263

37. Miyabe, H.; Asada, R.; Yoshida, K.; Takemoto, Y. Synlett 2004, 540-542. doi:10.1055/s-2004-815407

38. Miyabe, H.; Asada, R.; Takemoto, Y. Tetrahedron 2005, 61, 385-393. doi:10.1016/j.tet.2004.10.104

39. Miyabe, H.; Asada, R.; Toyoda, A.; Takemoto, Y. Angew. Chem., Int. Ed. 2006, 45, 5863-5866. doi:10.1002/anie.200602042

40. Miyabe, H.; Toyoda, A.; Takemoto, Y. Synlett 2007, 1885-1888. doi:10.1055/s-2007-984530

41. Yoshioka, E.; Kentefu; Wang, X.; Kohtani, S.; Miyabe, H. Synlett 2011, 2085-2089. doi:10.1055/s-0030-1261167

42. Miyabe, H.; Asada, R.; Takemoto, Y. Org. Biomol. Chem. 2012, 10, 3519-3530. doi:10.1039/c2ob25073j

43. Yoshioka, E.; Kohtani, S.; Sawai, K.; Kentefu; Tanaka, E.; Miyabe, H J. Org. Chem. 2012, 77, 8588-8604. doi:10.1021/jo3015227

44. Nishida, M.; Hayashi, H.; Nishida, A.; Kawahara, N. Chem. Commun. 1996, 579-580. doi:10.1039/cc9960000579

45. Hiroi, K.; Ishii, M. Tetrahedron Lett. 2000, 41, 7071-7074. doi:10.1016/S0040-4039(00)01213-2

46. Yang, D.; Gu, S.; Yan, Y.-L.; Zhu, N.-Y.; Cheung, K.-K. J. Am. Chem. Soc. 2001, 123, 8612-8613. doi:10.1021/ja016383y

47. Yang, D.; Gu, S.; Yan, Y.-L.; Zhao, H.-W.; Zhu, N.-Y. Angew. Chem., Int. Ed. 2002, 41, 3014-3017. doi:10.1002/1521-3773(20020816)41:16<3014::AID-ANIE3014>3.0.CO ;2-J

48. Yang, D.; Zheng, B.-F.; Gao, Q.; Gu, S.; Zhu, N.-Y. Angew. Chem., Int. Ed. 2006, 45, 255-258. doi:10.1002/anie. 200503056

49. Aechtner, T.; Dressel, M.; Bach, T. Angew. Chem., Int. Ed. 2004, 43, 5849-5851. doi:10.1002/anie.200461222 
50. Bauer, A.; Westkämper, F.; Grimme, S.; Bach, T. Nature 2005, 436, 1139-1140. doi:10.1038/nature03955

51. Breitenlechner, S.; Bach, T. Angew. Chem., Int. Ed. 2008, 47, 7957-7959. doi:10.1002/anie.200802479

52. Beeson, T. D.; Mastracchio, A.; Hong, J.-B.; Ashton, K.; MacMillan, D. W. C. Science 2007, 316, 582-585.

53. Jang, H.-Y.; Hong, J.-B.; MacMillan, D. W. C. J. Am. Chem. Soc. 2007, 129, 7004-7005. doi:10.1021/ja0719428

54. Conrad, J. C.; Kong, J.; Laforteza, B. N.; MacMillan, D. W. C. J. Am. Chem. Soc. 2009, 131, 11640-11641. doi:10.1021/ja9026902

55. Jui, N. T.; Lee, E. C. Y.; MacMillan, D. W. C. J. Am. Chem. Soc. 2010, 132, 10015-10017. doi:10.1021/ja104313x

56. Rendler, S.; MacMillan, D. W. C. J. Am. Chem. Soc. 2010, 132, 5027-5029. doi:10.1021/ja100185p

57. Pham, P. V.; Ashton, K.; MacMillan, D. W. C. Chem. Sci. 2011, 2, 1470-1473. doi:10.1039/c1sc00176k

58. Jui, N. T.; Garber, J. A. O.; Finelli, F. G.; MacMillan, D. W. C. J. Am. Chem. Soc. 2012, 134, 11400-11403. doi:10.1021/ja305076b

59. Nicolaou, K. C.; Reingruber, R.; Sarlah, D.; Bräse, S. J. Am. Chem. Soc. 2009, 131, 2086-2087. doi:10.1021/ja809405c

60. Nicolaou, K. C.; Reingruber, R.; Sarlah, D.; Bräse, S. J. Am. Chem. Soc. 2009, 131, 6640. doi:10.1021/ja902816z

61. Gansäuer, A.; Shi, L.; Otte, M. J. Am. Chem. Soc. 2010, 132 , 11858-11859. doi:10.1021/ja105023y

62. Gansäuer, A.; Behlendorf, M.; von Laufenberg, D.; Fleckhaus, A.; Kube, C.; Sadasivam, D. V.; Flowers, R. A., II. Angew. Chem., Int. Ed. 2012, 51, 4739-4742. doi:10.1002/anie.201200431

63. Gansäuer, A.; Klatte, M.; Brändle, G. M.; Friedrich, J. Angew. Chem., Int. Ed. 2012, 51, 8891-8894. doi:10.1002/anie.201202818

64. Streuff, J.; Feurer, M.; Bichovski, P.; Frey, G.; Gellrich, U. Angew. Chem., Int. Ed. 2012, 51, 8661-8664. doi:10.1002/anie.201204469

65. Curran, D. P.; Liu, W.; Chen, C. H.-T. J. Am. Chem. Soc. 1999, 121, 11012-11013. doi:10.1021/ja993329x

66. Nechab, M.; Campolo, D.; Maury, J.; Perfetti, P.; Vanthuyne, N.; Siri, D.; Bertrand, M. P. J. Am. Chem. Soc. 2010, 132, 14742-14744. doi:10.1021/ja106668d

67. Mondal, S.; Nechab, M.; Campolo, D.; Vanthuyne, N.; Bertrand, M. P. Adv. Synth. Catal. 2012, 354, 1987-2000. doi:10.1002/adsc.201200045

68. Mondal, S.; Nechab, M.; Vanthuyne, N.; Bertrand, M. P. Chem. Commun. 2012, 48, 2549-2551. doi:10.1039/c2cc17830c

69. Corminboeuf, O.; Renaud, P. Org. Lett. 2002, 4, 1731-1734. doi:10.1021/ol025799t

70. Corminboeuf, O.; Renaud, P. Org. Lett. 2002, 4, 1735-1738. doi:10.1021/ol0257981

71. Sibi, M. P.; Yang, Y.-H. Synlett 2008, 83-88. doi:10.1055/s-2007-992386

72. Evans, D. A.; Kozlowski, M. C.; Tedrow, J. S. Tetrahedron Lett. 1996, 37, 7481-7484. doi:10.1016/0040-4039(96)01697-8

\section{License and Terms}

This is an Open Access article under the terms of the Creative Commons Attribution License

(http://creativecommons.org/licenses/by/2.0), which permits unrestricted use, distribution, and reproduction in any medium, provided the original work is properly cited.

The license is subject to the Beilstein Journal of Organic Chemistry terms and conditions:

(http://www.beilstein-journals.org/bjoc)

The definitive version of this article is the electronic one which can be found at:

doi:10.3762/bjoc.9.128 